\title{
A theory for exaggerated secondary sexual traits in animal-pollinated plants
}

\author{
Jay M. Biernaskie $\cdot$ Elizabeth Elle
}

Published online: 2 October 2007

(C) Springer Science+Business Media B.V. 2007

Erratum to: Evol Ecol (Vol 21/4:459-472) (2007)
DOI 10.1007/s10682-006-9112-1

In the original of this article the contour plots did not match the axis labels Corrected fig 2

The online version of the original article can be found under doi: 10.1007/s10682-006-9112-1.

\section{J. M. Biernaskie $(\bowtie)$}

Department of Ecology \& Evolutionary Biology, University of Toronto, 25 Harbord Street, Toronto, Ontario, Canada M5S 3G5

e-mail: jmbierna@zoo.utoronto.ca

E. Elle

Behavioural Ecology Research Group, Department of Biological Sciences, Simon Fraser University, 8888 University Drive, Burnaby, British Columbia, Canada V5A 1 A6 e-mail: eelle@sfu.ca 
(a) $\operatorname{model} 2 \mathrm{a} ; z=0$

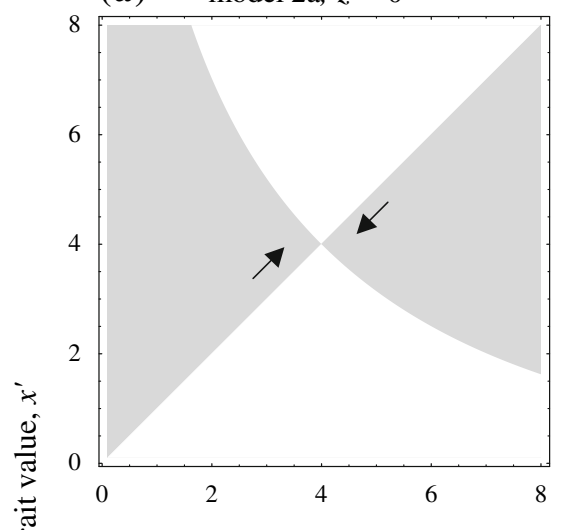

(c) model 2b; $z=0$

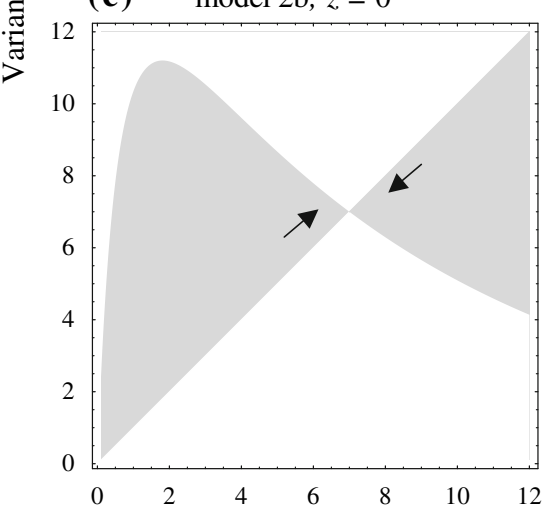

(b) model 2a; $z=0.4$

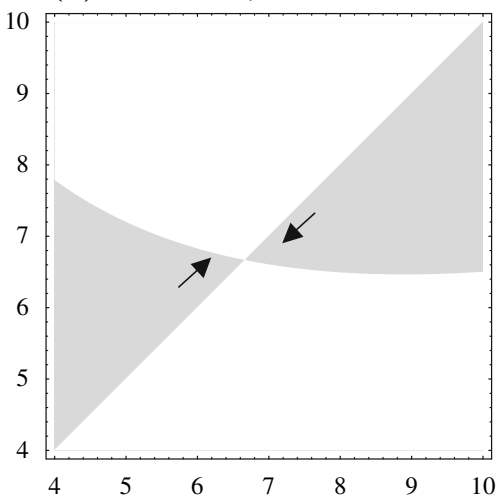

(d) $\quad$ model 2b; $z=0.4$

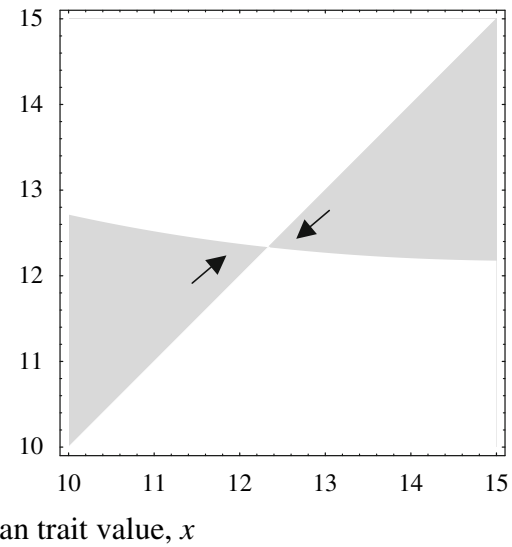

Fig. 2 Pairwise invasibility plots from models $2 \mathrm{a}[(\mathbf{a})$ and $(\mathbf{b})]$ and $2 \mathrm{~b}[(\mathbf{c})$ and $(\mathbf{d})]$, in cases where the attractiveness of a variant trait depends on its absolute value $x^{\prime}$ (with $z=0$ ) or its relative trait value in an asymmetric competition (with $z=0.4$ ). Contour lines indicate where $\left(x^{\prime}, x\right)=1$, and their intersection point is the candidate ESS $x^{*}$. Variant trait values can invade within the shaded regions, causing the population to evolve towards $x^{*}$. In all cases, $x^{*}$ is a convergence stable ESS, where no local variant can invade the population. All other parameter values are held constant at $=0.8,=0.8, c=0.1, g=0.1$. For comparison of ESS values, note the differences among axes 